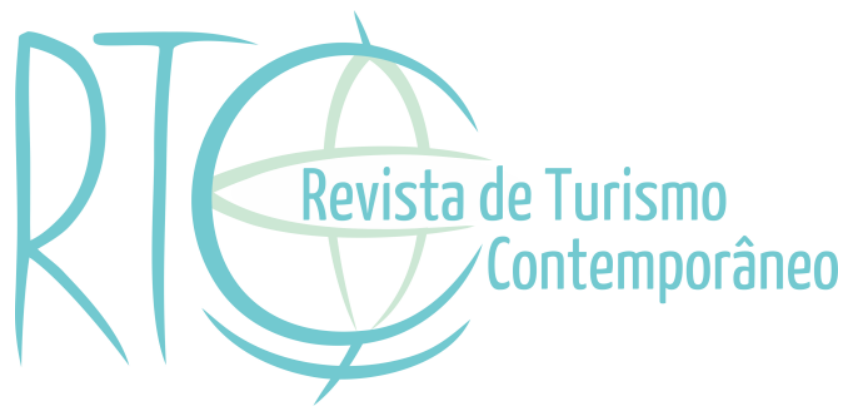

\title{
Produtos e serviços turísticos para a criança ofertados nos hotéis de Ouro Preto - MG
}

\author{
Tourist products and services for children offered at the \\ Ouro Preto hotels - MG
}

Harrison Bachion Ceribeli

Professor Adjunto da Universidade Federal de Ouro Preto - UFOP, Ouro Preto/MG, Brasil E-mail: harrisonbceribeli@hotmail.com

Amanda Alves Campos

Graduanda em Administração pela Universidade Federal de Ouro Preto - UFOP, Ouro Preto/MG, Brasil

E-mail: amandacampoos@yahoo.com.br

Artigo recebido em: $28-02-2018$

Artigo aprovado em: 05-12-2018 


\section{RESUMO}

Este trabalho teve como objetivo levantar a oferta de produtos e serviços turísticos voltados para o público infantil na cidade de Ouro Preto - MG. Como método de pesquisa, optou-se pelo estudo de casos múltiplos. Para seleção dos hotéis que seriam objeto de estudo, os pesquisadores acessaram o website de cada um dos hotéis de Ouro Preto e escolheram os cinco que possuíam mais informações acerca de serviços e atividades voltadas para o público infantil.A partir dos resultados obtidos, constatou-se que nenhumdos hotéis analisados possui profissionais especializados no atendimento do público infantil, como recreadores e babás, ou oferece atividades voltadas para crianças. Os hotéis também não possuem quartos personalizados parao público infantil; todos eles trabalham com a adição de camas e berços, quando solicitados pelos clientes. Ademais, a maioria não dispõe de playground ou brinquedoteca. Verifica-se, portanto, uma lacuna substancial de produtos e serviços turísticos voltados para as crianças no setor hoteleiro de Ouro Preto.

Palavras-chave:Turismo para crianças. Turismo infantil. Turismo em família.

\section{ABSTRACT}

This work aimed to identify the offer of tourist products and services for children in the city of Ouro Preto - MG. As a research method, the study of multiple cases was chosen. To select the hotels that would be the object of study, the researchers accessed the website of each Ouro Preto hotel and chose the five that had more information about services and activities focused on kids. Based on the results obtained, none of the hotels analyzed had professionals specialized in the care of children, such as recreators and nannies, or offered activities for this group. The hotels also do not have accommodations customized for children's segment; all of them work by adding beds and cots when requested by guests. In addition, most of them do not have playground or playroom. There is, therefore, a substantial gap in tourism products and services for children in the hotel industry in Ouro Preto.

Keywords:Tourism for kids. Children's tourism. Family tourism. 


\section{INTRODUÇÃO}

O Brasil é conhecido mundialmente por sua extensão territorial, por suas inúmeras belezas naturais, por sua cultura diversificada e suas regiões marcadas pela história, atraindo turistas de diversas localidades e também despertando nos brasileiros a curiosidade em conhecer o próprio país.

O turismo é uma atividade de grande importância econômica para o Brasil, pois,de acordo com Sakowski (2015), afeta os setores de transportes (aéreo, terrestre e aquaviário), de hospedagem, alimentação e agências de viagem. Em média,5\% da economia dos estados brasileiros depende dos recursos movimentados pelo turismo, sendo que alguns estados, como Rio de Janeiro, Distrito Federal e Rio Grande do Norte,têm a economia ainda mais ligada a esse setor(Sakowski,2015).

Ao final de 2014, os setores ligados ao turismo eram responsáveis por 2,04 milhões de ocupações no Brasil (2,2\% do total de ocupações no país),das quais $51 \%$ correspondem a vínculos formais de emprego(Instituto de Pesquisa Econômica Aplicada, 2016). Além disso, o Ministério do Turismo (2016a)calculou que a receita cambial gerada pelo Brasil em decorrência do turismo foi, em 2015, de 5,8 bilhões de dólares.

Em 2011, a pesquisa "Quem é o viajante brasileiro", conduzida pela revista Viagem e Turismo em parceria com o IBOPE Inteligência, traçou o perfil dos turistas domésticos eidentificou que $62 \%$ dos turistas são casados, $50 \%$ possuem filhos e $62 \%$ viajam com suas famílias. De forma complementar, a partir do levantamento feito pelo Instituto Brasileiro de Turismo (EMBRATUR, 2017), os turistasde países como Argentina, Paraguai, Chile, Uruguai, Bolívia e Suíça, que estão entre os principais pontos de origem de turistas estrangeiros que vêm ao Brasil, são, em grande parte, famílias.

Logo, é possível confirmar que existe uma grande demanda familiar por produtos e serviços turísticos e, consequentemente, para as crianças que compõem esses grupos familiares.De acordo com a Confederação Nacional do Turismo (CNTUR, 2012), o público que possui entre 35 e 50 anos com filhos prefere, normalmente, destinos que disponibilizemestrutura e atividades que atendam a todos os integrantes da família.

Partindo desse contexto, definiu-se como objetivo para o presente trabalho levantar a oferta de produtos e serviços turísticos voltados para o público infantil na cidade de Ouro Preto, estado de Minas Gerais.

De acordo com o Ministério do Turismo (2016b), Ouro Preto conta com uma cultura rica, marcada pela exploração de ouro e pedras preciosas, diversas igrejas e casarões antigos 
repletos de história, considerada como patrimônio mundial pelaUNESCO desde 1980. Somente devidoa eventos culturais, congressos, entre outros, a cidade recebe, em média, 500 mil visitantes por ano, de acordo com a Agência SEBRAE de Notícias (2011), o que evidencia o elevado potencial do local para atrair grande fluxo de turistas.

Como justificativa para o presente estudo, destacam-se dois fatores: primeiramente, a importância do turismo para a economia da cidade de Ouro Preto e a necessidade de identificar possíveis lacunas nos serviços prestados, com o intuito de atrair mais famílias; e, em segundo lugar, a escassez de estudos, na literatura nacional, que trata do tema turismo infantil, apesar de sua relevância.

\section{REFERENCIAL TEÓRICO}

\subsection{Turismo infantil}

Segundo Vaz (1999), o turismo infantil refere-se às atividades turísticas projetadas para atender aos anseios de indivíduos dos sete aos 13 anos. Por sua vez, Kushano (2013), ampliando o conceito, definiu turismo infantil como a atividade turística realizada por crianças e preparada especificamente para elas, ainda que estejam assistidas por seus familiares e/ou responsáveis.

Deve-se considerar, portanto, que a terminologia "turismo infantil" não deve ser compreendida somente sob o prisma da faixa etária atendida, à medida que faz emergir a necessidade de se planejarem as atividades turísticas voltadas para o público infantil visando proporcionar às crianças uma experiênciacondizente com suaspercepções e visão do mundo,adequada a suas demandas, que seja segura, humanizada e de qualidade, e que contribua para seu bem-estar, conforto, entretenimento, enriquecimento cultural e desenvolvimento pessoal(Kushano, 2013).

O turismo infantil, em sua essência, está presente em diversos contextos, sendo as opções mais comuns encontradas no mercado os "acampamentos de férias, os acantonamentos, a hospedagem em hotéis de lazer e resorts, a diversão nos parques temáticos e o turismo pedagógico" (Kushano, 2008, p. 66).

De acordo com Rhoden, Hunter-Jones e Miller(2016), as crianças formam um grupo exigente quanto aos locais de visitação e produtos/serviços que lhes são oferecidos, esperando mais do que estruturas básicas de hospedagem.

Neste sentido, Kushano (2008) argumenta que o público infantil representa uma demanda por mão de obra especializada em recreação de crianças dentro do ramo hoteleiro, 
principalmente para os hotéis e resorts cuja atuação tem como foco proporcionar aos clientes lazer e diversão.

O planejamento do turismo infantil é atividade complexa e envolve diversos elementos, pois, para crianças entre nove e 10 anos, tanto as experiências tangíveis quanto as intangíveis possuem grande importância, o que engloba desde a estrutura da acomodação disponível até a possibilidade de se estabelecerem novas amizades (Rhoden, Hunter-Jones, \& Miller, 2016).

Importante esclarecer que o adequado planejamento das atividades de turismo infantil não tem como único intuito propiciar uma experiência memorável a esse público, mas também aumentar a atratividade da programação voltada para a família de modo geral, principalmente porque as crianças de pouca idade tendem a influenciar as escolhas das férias em família (Khoo-Lattimore, Praya, \& Cheah, 2015), considerando que são recorrentes os casos nos quais o programa de férias é idealizado e escolhido pelos pais ou responsáveis em prol dos filhos (Shaw, Havitz, \& Delemere, 2008).

A estrutura hoteleira do Brasil voltada para o público infantil foi descrita por Kushano (2008) e inclui alguns hotéis que oferecem serviços, acomodações e até mesmo marketing diferenciado para as crianças. Ainda segunda a mesma autora, são ofertadas programações para o dia todo voltadas para esse segmento; espaços infantis temáticos com jogos e filmes; práticas de recreação que envolvem atividades ao ar livre de todos os tipos, como brincadeiras na piscina, escaladas, aulas de surf e passeio a cavalo; produtos diferenciados, como aulas de circo, ordenha de vaca e cultivo de horta; mini zoológico; e aquário. Alguns hotéis disponibilizam atividades que os pais podem desenvolver junto com os filhos, enquanto outros possuem espaços exclusivos para crianças (Kushano, 2008).

Em relação às facilidades voltadas para o público infantil no setor de turismo, são oferecidos serviços de babás nos hotéis, cardápios e horários direcionados para a alimentação infantil nos restaurantes, alémde espaços reservados para preparo da alimentação de bebês (Kushano, 2007).

\subsection{Pesquisas recentes abordando a temática turismo infantil}

Poucas são as pesquisas que, até a atualidade, abordaram o tema turismo infantil e, considerando um horizonte temporal mais recente, a literatura é ainda mais escassa, seja em âmbito nacional quanto internacional. Além disso, conduzindo um levantamento bibliográfico 
em bases como Scielo e Scopus, percebeu-se que parte dos poucos estudos que perpassam por esse assunto muitas vezes direcionam a discussão para o turismo em família.

Entre as publicações que versaram sobre essa temática, tem-se, por exemplo, o trabalho de Fu, Lehto e Park (2014), que analisou como as férias familiares são percebidas. A partir dos resultados obtidos, constatou-se que esse tipo de evento é visto como um momento de afastamento do cotidiano, com o intuito de relaxar e se desligar do dia a dia estressante, além de uma maneira de recarregar as energias. Além disso, observou-se que as férias em família são consideradas experiências que intensificam a ideia e o sentimento de união, auxiliando no fortalecimento de vínculos. Por fim, identificou-se que, para os pais, as férias familiares possuem elevado valor e, por isso, eles desenvolvem mais expectativas do que as crianças e desejam que os filhos se mantenham entretidos e que este momento também seja parte de um processo educativo.

De forma complementar, o estudo de Schänzel e Smith (2014) indicou que, a priori, as famílias são diferentes de outros grupos e que é necessário que haja um adequado planejamento para lhes possibilitar uma experiência turística em grupo, à medida que, durante o período de férias, os familiares que viajaram juntos preferem momentos coletivos em relação aos individuais. Complementarmente, o referido estudo também destacou que, embora haja certa preferência pelos momentos coletivos, as experiências de lazer individuais não devem ser negligenciadas, sendo importante conciliar essas duas abordagens para proporcionar experiências de maior qualidade.

O estudo de Lamb (2016), por sua vez, trouxe algumas reflexões de gestores de instalações de lazer acerca do turismo em família. A partir dos resultados encontrados pelo autor supracitado, conclui-se que tais profissionais reconhecem que as famílias são clientes potenciais para os serviços turísticos, apesar de relatarem diversas dificuldades para atenderem às demandas familiares de lazer. Os gestores entrevistados também listaram várias possibilidades de serviços que podem ser ofertados às famílias, como estacionamento preferencial, oferta de transporte para famílias sem veículos, creche, ambientes recreativos dentro das instalações, atividades envolvendo pais e filhos, e menores taxas de entrada.

Adotando outra linha de investigação, tem-se a pesquisa de Carneiro et al. (2015), cujo intuito foi levantar os atributos valorizados por crianças e adolescentes na escolha dos destinos turísticos. De acordo com os resultados encontrados por esses autores, as rotas que mais atraem esse público são aquelas que envolvem o contato com a água, seja em praias ou piscinas, e que permitem que sejam realizadas atividades em família ou com amigos. 
Corroborando os achados de Carneiro et al. (2015), a pesquisa conduzida por Rhoden, Hunter-Jones e Miller (2016), que teve como objetivo compreender questões relativas às experiências infantis no turismo, indicou que as crianças valorizam tanto os elementos tangíveis de suas experiências turísticas, como as acomodações, quanto os intangíveis, como as relações propiciadas pela viagem. Além disso, os resultados obtidos permitiram concluir que tanto os recursos naturais, como praias e paisagens, quanto os recursos artificiais, como piscinas e escorregadores, influenciam de maneira positiva a percepção das crianças turistas acerca de seu período de férias.

Complementarmente, tem-se o estudo de Jelínková, Tučková eJurigová(2017), cujo propósito foi identificar as necessidades e preferências das famílias com crianças em relação aos hotéis onde se hospedam durante as viagens. Esses autores concluíram que as famílias são um público-alvo de grande potencial e que é preciso que o ramo hoteleiro se adapte a elas, proporcionando instalações, serviços e atividades recreativas adequadas a suas necessidades. Além disso, constataram que as famílias preferem viagens mais curtas quando os filhos estão em idade pré-escolar e, depois que eles ultrapassam essa fase, optam por viagens mais longas e com mais atividades. Por fim, os resultados obtidos indicaram que as famílias gostariam que os hotéis disponibilizassem mais atividades para recreação infantil, serviços de babá, parques recreativos, cardápios especiais para crianças e venda ou locação de produtos esportivos, como bicicletas, bolas, triciclos, entre outros.

Finalizando, tem-se o trabalho de Khoo-Lattimore, Praya e Cheah (2015), que conduziu uma reflexão a respeito das pesquisas na área de turismo que são focadas no público infantil. Tal estudo confirmou a crescente influência que as crianças exercem no planejamento das férias em família e indicou algumas abordagens que devem ser utilizadas para conduzir grupos focais quando os participantes são muito jovens.

\section{ASPECTOS METODOLÓGICOS}

A presente pesquisa pode ser classificada como descritiva, pois teve como propósito descrever/caracterizar o objeto estudado (Gil, 2008), ou seja, os serviços hoteleiros voltados para o público infantil. Adotou-se uma abordagem qualitativa, que se baseia em uma investigação mais aprofundada de um objeto e que busca interpretá-lo e compreendê-lo em sua totalidade; ao contrário da abordagem quantitativa, a pesquisa de caráter qualitativo não se atém à aplicação de técnicas estatísticas para análise dos dados coletados, pois o intuito é aprofundar a compreensão que se tem acerca do tema em questão. 
Como método de pesquisa, optou-se pelo estudo de casos múltiplos, que consiste em um conjunto de dois ou mais estudos de caso, adotando-se a mesma metodologia, o que permite a comparação dos resultados obtidos em cada um deles (Jesus \& Cunha, 2016). Como vantagens do estudo de casos múltiplos, têm-se a possibilidade de alcançar resultados mais consistentes e categóricos, que forneçam uma visão mais global do objeto analisado (Yin, 2001), o que justifica a opção por esse método.

Para coleta de dados, foram empregadas três técnicas distintas: análise das informações disponibilizadas nos websites das empresas estudadas, observação in loco e entrevistas em profundidade com gestores de hotéis.

Por meio da observação in loco, que ocorreu junto com a realização das entrevistas, foi possível conhecer as instalações dos hotéis selecionados para estudo, além de confirmar as informações existentes nos respectivos websites e também aquelas que foram repassadas aos pesquisadores pelos entrevistados.

Já as entrevistas em profundidade permitiram questionar os gestores dos hotéis acerca da existência de acomodações voltadas para famílias com crianças, espaços lúdicos dentro de suas instalações, atividades voltadas para o público infantil, profissionais especializados na recreação e supervisão das crianças turistas, e cardápio para atender tal público; em suma, coletar dados a respeito de como as organizações se preparam para atender o turismo infantil.

A entrevista em profundidade consiste em um procedimento que permite a coleta de dados com maior maleabilidade, propiciando ao entrevistado a possibilidade de elaborar suas falas sem estar limitado ao rigor de respostas diretas elaboradas previamente pelo entrevistador, como em questionários (Oliveira, Martins, \& Vasconcelos, 2012). Tal método possui como vantagens a fundamentação dos resultados obtidos na realidade do entrevistado, considerando que sua fala durante a entrevista é livre, assim como uma melhor exploração das particularidades relacionadas ao assunto abordado.

A população do presente estudo englobou os hotéis localizados na cidade de Ouro Preto, Minas Gerais. A escolha de Ouro Preto, reconhecida pela UNESCO em 1980 como Patrimônio Histórico da Humanidade, justifica-se com base em sua grande importância histórica para o país e o estado onde se situa, o que a torna um destino turístico bastante procurado. De acordo com o Ministério do Turismo (2017), a cidade se encontra na categoria $\mathrm{B}$, que agrupa 5\% dos municípios categorizados; juntos, os municípios das categoria A e B respondem por $68 \%$ do fluxo doméstico brasileiro e $97 \%$ do internacional.

Para seleção dos hotéis que seriam objeto de estudo, os pesquisadores acessaram o website de cada um dos hotéis de Ouro Preto e escolheram os cinco que possuíam mais 
informações acerca de serviços e atividades voltadas para o público infantil. Em seguida, contataram-se os gestores das organizações selecionadas, com o intuito de verificar a possibilidade de participarem da pesquisa.

O Hotel A atua no mercado desde 2008. Possui uma localização central a 680 metros da Praça Tiradentes, local de destaque na cidade de Ouro Preto, com grande número de estabelecimentos comerciais e intenso fluxo de turistas. A estrutura do estabelecimento inclui 19 apartamentos, classificados em standard, luxo e suíte máster, dois estacionamentos com cobertura, sala de internet, duas sala para reuniões (para eventos sociais e empresariais) e internet wireless. Sua área de lazer oferece sauna, piscina, mini academia e mini salão de jogos, com bilhar, tênis de mesa e vôlei. Possui como diferencial uma mina de ouro aberta à visitação de hóspedes no interior do hotel. Em sua diária, está incluso o café da manhã; além disso, a estadia para uma criança de até cinco anos é gratuita e para duas crianças de até cinco anos uma estadia é gratuita e a outra tem um custo reduzido.

O Hotel B foi inaugurado em 2009 e está localizado no centro de Ouro Preto, próximo de uma das históricas Igrejas da cidade. Sua estrutura é a de um casarão do século XX, dispondo de 22 quartos classificados em standard, luxo, superior e superior com hidromassagem. As acomodações são adaptadas para não fumantes, famílias e pessoas com deficiência. O hotel ainda possui uma sala de estar ampla, com televisão, som e lareira; salão de café; e sala de ginástica. Sua área de lazer conta com mesa ping-pong e duas piscinas, uma para adultos e outra para crianças.

O Hotel C é um casarão do século XIX e funciona desde 1840, estando localizado na parte central da cidade de Ouro Preto. Sua estrutura conta com 41 apartamentos classificados nas modalidades small, standard, ouro, ouro triplo, suítes executivas e suítes superiores. Possui restaurante, bar, adega, espaço para eventos e espaço fitness. Disponibiliza serviços como lavanderia, internet wireless, estacionamento com motorista, serviço de mensageiro e serviço de quarto. Em sua área de lazer estão dispostas duas piscinas, uma ao ar livre e a outra com cobertura, aquecimento e hidromassagem.

O Hotel D foi fundado em 1971, está localizado no centro histórico de Ouro Preto e foi instalado em um casarão do século XVIII. Possui 18 acomodações divididas em apartamentos, suítes-mezanino e suítes-varanda. O hotel está estruturado de maneira acessível, e disponibiliza televisão com canais pagos, incluindo os infantis. Oferta serviços de quarto, estacionamento, café da manhã, serviço de despertar, lavanderia, recepção 24 horas e quartos para família. 
Por fim, o Hotel E está localizado no centro de Ouro Preto, funcionando na cidade desde 2009. O estabelecimento dispõe de oito quartos, divididos nas categorias luxo e superluxo, que possuem adaptações para não fumantes e famílias, canais pagos na televisão que incluem programação infantil, sistema de aquecimento e ventilador. Seu serviço de alimentação é ofertado em parceria com um café e restaurante local. Dispõe de serviços receptivos, como traslados do aeroporto de Confins, em Belo Horizonte, até a cidade de Ouro Preto. Possui também salas de reunião, realiza locação de carros e ainda oferece programas de lazer para os hóspedes, como passeios ecológicos e radicais nas cidades de Ouro Preto, Mariana, Congonhas e Tiradentes.

Para analisar os dados coletados, empregou-se a técnica de Análise de Conteúdo, que possibilita descrever de forma estruturada o material analisado (nesse caso, os dados coletados nas entrevistas). De acordo com Bardin (1977), essemétodo pode ser executado adotando-se diferentes unidades de análise. Nopresente estudo, porém, foram utilizadas como unidades de análise os temas abordados durante as entrevistas.

\section{APRESENTAÇÃO E DISCUSSÃO DOS RESULTADOS}

A seguir, são descritos, inicialmente, os produtos e serviços voltados para o público infantil que são disponibilizados por cada um dos cinco hotéis estudados. Posteriormente, apresenta-se uma análise comparativa dos casos, conduzida a partir do referencial teórico previamente consultado, assim como uma reflexão crítica acerca dos resultados encontrados e suas implicações para as crianças turistas e seus pais ou responsáveis.

\subsection{Hotel A}

O hotel A não possui funcionários que trabalham exclusivamente com crianças e também não disponibiliza profissionais terceirizados para acompanharem o público infantil. As acomodações seguem o mesmo padrão, independentemente de se destinarem ao público adulto ou infantil, sem nenhuma diferenciação, sendo que um quarto pode ser composto por uma cama de casal e até quatro camas de solteiro; em caso de crianças menores, berços podem ser colocados no quarto de casal.

A organização não disponibiliza nenhumaatividade de recreação ou programação diferenciada para o público infantil, etambémnãopossui um cardápio adaptado a esse segmento específico. Fica claro, portanto, o foco exclusivo no público adulto e a necessidade de as crianças turistas adequarem-se ao que é oferecido a seus pais ou responsáveis. 
Por outro lado, oferece aos hóspedes um espaço reservado para o preparo de refeições para bebês, além de uma piscina e um playground, sendo este últimoo únicoespaço dentro de suas instalações voltado para atender especificamente o público infantil. O hotel ainda dispõe de uma mina de ouro que pode ser visitada dos hóspedes; a visita ao local pode ser realizada pelos pais e filhos juntos.

\subsection{Hotel B}

O hotel B não tem em seu quadro de pessoal nenhum profissional responsável por acompanhar as crianças e também não contrata uma empresa terceirizada para prestar esse tipo de serviço. Os quartos não possuem nenhuma diferenciação para atender adultos e crianças, sendo possível, contudo, alocar até três camas de solteiro, além da cama de casal, na mesma acomodação. Caso seja feita uma solicitação antecipada, pode-se colocar um berço no quarto de casal.

Nenhuma programação ou atividade recreativa direcionada às crianças é ofertada pela organização, assim como também não há espaço para preparo de refeições para bebês e cardápio adaptado ao público infantil.Portanto, as crianças têm que se adequar à estrutura disponível para atender a seus pais ou responsáveis.

O hotel disponibiliza uma brinquedoteca, que consiste em um espaço no qual estão disponíveis alguns brinquedos para as crianças, além de uma piscina somente para o público infantil, sendo essas as partes de suas instalações que são voltadas para a recreação dos hóspedes mais jovens.

\subsection{Hotel C}

$\mathrm{O}$ hotel $\mathrm{C}$ não possui funcionários responsáveis por acompanharem as crianças que estejam nele hospedadas em companhia dos pais ou responsáveis e nem contrata um serviço terceirizado para essa finalidade. Suas acomodações incluem quartos para famílias com crianças, que podem ser equipados com uma cama de casal e outras duas de solteiro, ou ainda uma cama de casal, um berço e uma cama de solteiro.

A organização não oferta nenhuma atividade recreativa ou programação voltada para o público infantil, além de não contar, em sua estrutura, com playground, brinquedoteca ou qualquer espaço exclusivo para crianças. Como opção de lazer, disponibiliza apenas piscinas adulto e infantil, ou seja, não há nenhum espaço com características lúdicas para atender aos anseios das crianças. 
Finalmente, apesar de não contar com um espaço voltado especificamente para o preparo de refeições para bebês, o hotel C possui um cardápio adaptado para crianças, disponibilizando opções de pratosadequadasàs preferências alimentares tradicionaisdo público infantil.

\subsection{Hotel D}

No hotel D não há nenhum profissional que trabalha com foco nas crianças, sendo que esse serviço também não é terceirizado. Nas acomodações voltadas para as famílias com filhos, é possível acrescentar quantas camas de solteiro forem necessárias ou ainda berços.

O único serviço disponibilizado para o público infantil é o café da manhã personalizado, em que parte do cardápio é adaptado para atender às crianças, quando este público está hospedado no local.

Nenhuma estrutura recreativa é oferecida pelo hotel D ao público infantil, ou seja, não há playground, brinquedoteca, piscina ou qualquer outro espaço de lazer para as crianças que estão hospedadas nele. Ademais, não há nenhuma programação ou atividade direcionada para a recreação dos hóspedes mais jovens.

\subsection{Hotel E}

Assim como os quatro anteriores, o Hotel E não possui em seu quadro de funcionários profissionais que trabalhem com o público infantil. Quanto às acomodações, é possível se hospedar até quatro pessoas em um mesmo quarto, alocadas em uma cama de casal e duas camas de solteiro ou, ao invés dessas últimas, berços.

No que se refere à alimentação, a organização, apesar de não oferecer um espaço específico para preparação de refeições de bebês, trabalha com cafés da manhã personalizados, possibilitando que os hóspedes solicitem a introdução de alimentos normalmente não inclusos no cardápio, desde que haja disponibilidade, sendo esse um serviço não limitado ao público infantil.

O hotel E não tem, em sua estrutura, playground, brinquedoteca ou qualquer outro espaço infantil, e somente possui uma piscina, que pode ser utilizada por adultos e crianças. Além disso, não disponibiliza nenhum tipo de atividade ou programação voltada para recreação dos hóspedes mais jovens. 


\subsection{Análise comparativa}

Em nenhum dos hotéis estudados há profissionais especializados no atendimento ao público infantil, como recreadores e babás; além disso, nenhum oferece atividades voltadas para crianças. A ausência de serviços direcionados ao público infantil pode influenciar negativamente a maneira como os pais ou responsáveis percebem o hotel onde se hospedaram (Khoo-Lattimore, Praya, \& Cheah, 2015).Ademais, não é possível ignorar que as crianças têm elevadas expectativasquanto aos locais em que ficarão hospedadas e serviços que lhes são ofertados (Rhoden, Hunter-Jones, \& Miller, 2016), frustrando-se quando encontram apenas uma estrutura básica, que não atenda a seus anseios infantis.

Com isso, verifica-se que é necessário que se mude a mentalidade de que adisponibilização de atividades voltadas para o público infantilésomente um meio de ofertar uma experiência marcante às crianças, pois também é uma forma de atrair mais famílias e satisfazer os hóspedes, ainda mais ao se considerar que a falta de uma programação diferenciada ou recreação infantil pode resultar em descontentamento dos clientes(KhooLattimore, Praya, \&Cheah, 2015; Shaw, Havitz, \&Delemere, 2008).

Os hotéis estudados não possuem quartos personalizados para o público infantil; todos eles trabalham com a adição de camas e berços, quando solicitados pelos clientes; também não possuem nenhum serviço voltado para crianças.Entretanto, é importante que se compreenda que as famílias não são iguais a outros grupos turísticos e deveriam ser tratadas de acordo com suas particularidades (Schänzel \& Smith, 2014).

Quanto às estruturas de lazer disponíveis, somente um hotel tem playground, um tem uma brinquedoteca e quatro possuem piscina. Importante destacar que investir em recursos como esses é importante, pois torna a experiência das crianças mais rica.

E, embora a maior parte dos locais estudados disponha de pouca estrutura, serviços e atividades voltadas para o público infantil, é possível observar, mesmo que de forma precária e insuficiente, tentativas de adequação às demandas familiares dos hóspedes.

O Hotel A, por exemplo, é o único que possui playground para as crianças e ainda conta com um espaço para preparação de refeições para bebês e uma mina aberta aos hóspedes,que pais e filhos podem visitar juntos, sendo essa atividade conjunta algo bastante positivo na visão de Fu, Lehto e Park (2014), que defendem que as férias em família devem servir para tornar mais forte o sentimento de união entre seus membros e estreitar vínculos. Além disso, conforme argumentam Schänzel e Smith (2014), os indivíduos que viajam acompanhados de seus familiares preferem momentos coletivos em relação aos individuais. 
O Hotel B, por sua vez, destaca-se por possuir uma piscinapara adultos e outra para o público infantil, além de contar com uma brinquedoteca. O Hotel C, que também disponibiliza piscinas diferentes para adultos e crianças, ainda disponibiliza um cardápio infantil, o que se torna um fator facilitador da estadia de pais ou responsáveis que estão acompanhados por crianças.

Já o Hotel D disponibiliza café da manhã personalizado para o público infantil, o que, conforme supracitado, facilita a estadia dos adultos e, ao mesmo tempo, torna a experiência das crianças mais agradável e prazerosa.

Para concluir, percebe-se que os hotéis pesquisados, de modo geral, possuem uma estrutura bastante incompleta para atender ao público infantil, principalmente se forem considerados os atributos de locais devidamente preparados, que costumam contar com programações para o dia todo voltadas para crianças, espaços infantis temáticos e atividades ao ar livre (Kushano, 2008).

\subsection{Análise crítica dos resultados encontrados}

Refletindo acerca dos resultados encontrados a partir da análise comparativa dos cinco casos estudados, chama atenção, em primeiro lugar, a falta de profissionais contratados pelos hotéis para supervisionarem as crianças turistas e de atividades voltadas para elas, o que faz com que os pais ou responsáveis tenham que se decidir entre colocar em segundo plano suas preferências de passeios, priorizando o atendimento das demandas infantis, ou levar as crianças para os acompanharem nos "passeios de adulto". Destaca-se, todavia, que tanto em uma quanto na outra situação um dos dois grupos etários tende a se frustrar pela escassez de diversão apropriada a seus próprios anseios e expectativas.

Nessa mesma linha, deve-se ponderar a respeito do fato de que, apesar de estarem localizados em uma cidade histórica, repleta de museus, como a Casa dos Contos, o Museu da Inconfidência, a Estação Ferroviária, o Museu do Aleijadinho e o Museu de Ciência e Técnica da Escola de Minas (UFOP), nenhum dos cinco hotéis estudados explora esse tipo de passeio, fornecendo um acompanhante para as crianças durante a visita a esses locais.

Com isso, os pais ou responsáveis, ao visitarem os museus de Ouro Preto, muitas vezes acabam perdendo detalhes riquíssimos da história que é contada por meio das obras e objetos expostos devido à necessidade de monitorarem continuamente as crianças. Ao mesmo tempo, pela ausência de uma abordagem e de uma linguagem que lhes são apropriadas, as crianças não se enriquecem culturalmente tanto quanto seria possível. 
De forma complementar, cabe ressaltar queas organizações estudadas pecam, sob a ótica do turismo infantil, por não disponibilizarem acomodações e nem espaços com características lúdicas, que contribuiriam para a diversão das crianças durante sua estadia e também para formar, nos pais ou responsáveis, a percepção de que as instalações do hotel no qual estão hospedados foram cuidadosamente pensadas para proporcionarem uma experiência diferenciada para o público infantil.

Ao contrário, quando os pais ou responsáveis são informados pelo hotel - e isso normalmente ocorre no contato que é feito antes da reserva ou no momento em que a família chega - de que os quartos para famílias com crianças diferenciam-se exclusivamente pela existência, além das camas de casal, de camas de solteiro e/ou berços, e de que não háespaços específicos para as crianças brincarem, acabam formando uma percepção de que o público infantil não encontrará ali um local adequado a suas demandas, as quais terão que ser supridas "da porta do hotel para fora".

Finalmente, resgatando o Artigo $4^{\circ}$ do Estatuto da Criança e do Adolescente, Lei $n$. 8.069 (1990), que enuncia que é dever da família, comunidade, poder público e sociedade em geral assegurar, às crianças, o direito, entre outros pontos, ao lazer e à cultura, questiona-se se, nos casos estudados, assim como em outros hotéis nos quais as condições aqui descritas repetem-se, o público infantil está sendo devidamente respeitado.

\section{CONSIDERAÇÕES FINAIS}

O turismo é uma atividade que movimenta significativamente a economia do Brasil, gerando renda e empregando milhares de pessoas. Entre os principais públicos que buscam os destinos turísticos nacionais, destacam-se as famílias, que muitas vezes têm demandas particulares, devido às necessidades e expectativas das crianças, as quais muitas vezes acabam sendo desprezadas no setor hoteleiro.Com isso, definiu-se como objetivo de pesquisa levantar a oferta de produtos e serviços turísticos voltados para o público infantil na cidade de Ouro Preto - Minas Gerais.

Analisando cinco hotéis, escolhidos depois de se analisarem os websites de todos os estabelecimentos dessa natureza localizados em Ouro Preto, constatou-se que a principal opção de lazer para as crianças nesses locais são as piscinas. Playgrounds e brinquedotecas normalmente não fazem parte da estrutura hoteleira local. 
Quanto às acomodações disponíveis, não há nenhuma característica nos quartos cujo objetivo seja tornar a estadia das crianças mais lúdica ou acolhedora. Os hotéis apenas acrescentam camas de solteiros ou berços, caso os hóspedes solicitem.

Os hotéis estudados também não têm profissionais que atendam ao público infantil e nem disponibilizam atividades ou qualquer programação para distrair e entreter as crianças, com exceção de um deles, que permite que pais ou responsáveis visitem uma mina com seus filhos ou tutelados.

Por fim, na parte da alimentação, foram encontrados dois estabelecimentos que possuem um cardápio que visa atender, mesmo que de maneira parcial, o público infantil, e um que dispõe de um local específico destinado ao preparo de refeições para bebês.

Percebe-se, portanto, que os hotéis da cidade possuem uma estrutura simples e uma oferta básica de produtos e serviços para o público infantil, evidenciando-se uma lacuna a ser sanada, com o intuito de tornar a estadia das famílias que vão a Ouro Preto mais prazerosa.

Como alternativas de melhoria dos produtos e serviços turísticos voltados para grupos familiares, sugerem-se três caminhos: (1) a contratação de profissionais para acompanharem as crianças e planejarem atividades lúdicas com elas, ou ainda a disponibilização do serviço de babá; (2) o aprimoramento dos cardápios, tornando-os mais apropriados a hóspedes de diferentes faixas etárias; e (3) a criação de locais destinados à recreação das crianças, como playgrounds e brinquedotecas.

A contribuição gerencial dessa pesquisa reside na identificação de algumas lacunas nos estabelecimentos hoteleiros de Ouro Preto, que, apesar de serem amplamente procurados por famílias interessadas em conhecer a cidade e sua história, não estão preparados para atendê-las adequadamente.Academicamente, a presente pesquisa contribui ao estimular uma discussão ainda embrionária na literatura, pois, por enquanto, poucas investigações são encontradas sobre turismo infantil.

Para pesquisas futuras, sugere-seque sejam analisadas as condições de hospedagem em outras cidades históricas do Brasil, com o intuito de identificar se a lacuna mapeada em Ouro Preto se estende a outras localidades. Ademais, sugere-se que sejam mapeadas as expectativas dos pais ou responsáveis, que viajam com crianças, acerca da estrutura hoteleira que gostariam de encontrar nas cidades visitadas. 


\section{REFERÊNCIAS}

Agência do Serviço Brasileiro de Apoio às Micro e Pequenas Empresas (SEBRAE) de Notícias. (2011). Ouro Preto lucra com eventos e recebe 500 mil turistas por ano.

Recuperado em 15, fevereiro, 2018, de http://www.mg.agenciasebrae.com.br/sites/asn/uf/MG/ouro-preto-lucra-com-eventos-erecebe-500-mil-turistas-por-ano,f45b478751d16410VgnVCM1000003b74010aRCRD

Bardin, L. (1977).Análise de conteúdo. Lisboa: Edições 70.

Carneiro, M. M. C., Veloso, A. R., Ferraz, S. B., \&Campomar, M. C. (2015). Os atributos valorizados por crianças e adolescentes na escolha de destinos turísticos. Revista Turismo: Visão e Ação, 17(2), 475-507.

CNTUR. (2012). Perfil do Turista e dos Segmentos de Oferta - Percepções e Comportamentos. Recuperado em 15, fevereiro, 2018, de https://www.sebraemg.com.br/atendimento/bibliotecadigital/documento/Cartilha-Manual-ouLivro/Perfil-do-Turista-e-dos-Segmentos-de-Oferta---Percepcoes-e-Comportamentos

EMBRATUR. (2017). O perfil do turista e a imagem do Brasil. (3a ed.). Brasília: Boletim de Inteligência Competitiva.

Fu, X.,Lehto, X.,\&Park, O. (2014). What does vacation do to our family? Contrasting the perspectives of parents and children. Journal of Travel \& Tourism Marketing, 31(4), 461-475.

Gil, A. C. (2008).Métodos e técnicas de pesquisa social. (6a ed.). São Paulo: Atlas.

IPEA. (2016).Sistema de informações sobre o mercado de trabalho do setor turismo.Recuperado em 27, fevereiro, 2018, de

http://www.ipea.gov.br/extrator/arquivos/161018_oficina_geral_sistema_informacoess_sobre _mercado_trabalho_setor_turismo.pdf

Jelínková, D., Tučková, Z., \&Jurigová, Z. (2017). Market segment of families with children: a new stimulus for modern Czech spa industry? Journal of International Studies, 10(2), 158169.

Jesus, W. F., \& Cunha, C. (2016). A pesquisa em educação no Brasil: novos cenários e novos olhares. Brasília: Liber Livro.

Khoo-Lattimore, C., Praya, G., \& Cheah, B. L. (2015).Kids on board: methodological challenges, concerns and clarifications when including young children's voices in tourism research.CurrentIssues in Tourism, 18(9),845-858.

Kushano, E. S. (2007). A importância do brincar e do turismo na infância - um olhar para a Brinquedoteca Keka\& Companhia, Itabuna, Bahia. Caderno Virtual de Turismo, 7(3),35-45.

Kushano, E. S. (2008).Adequação de produtos e serviços turísticos para a criança: um olhar para os meios de hospedagem. Dissertação de Mestrado em Cultura \& Turismo, Universidade Estadual de Santa Cruz, Bahia. 
Kushano, E. S. (2013). Turismo infantil: uma proposta conceitual. Turismo e Sociedade, 6(1), 124-146.

Lamb, D. (2016). Closing the gap in family leisure provision: giving leisure facility managers the opportunity to reflect on what they provide for families. Managing Sport andLeisure, 21(1), 44-60.

Lei n.8.069 13 de julho de 1990.(1990). Dispõe sobre o Estatuto da Criança e do Adolescente e dá outras providências. Recuperado em 15, outubro, 2018, de http://www.planalto.gov.br/ccivil_03/LEIS/L8069.htm

Ministério do Turismo. (2017).Categorização dos municípios das regiões turísticas do mapa do turismo brasileiros. Recuperado em 15, fevereiro, 2018, de http://www.turismo.gov.br/sem-categoria/5854-categorização-dos-municípios-das-regiõesturísticas-do-mapa-do-turismo-brasileiro.html

Ministério do Turismo. (2016a). Estatísticas básicas de turismo: Brasil, ano base 2015. Brasília: Ministério do Turismo,Secretaria Nacional de Políticas de Turismo.

Ministério do Turismo. (2016b). Encantos e surpresas de Ouro Preto. Recuperado em 15, fevereiro, 2018, de http://www.turismo.gov.br/\%C3\%BAltimas-not\%C3\%ADcias/6197-osencantos-e-surpresas-de-ouro-preto.html

Oliveira, V. M., Martins, M. F., \& Vasconcelos, A. C. (2012). Entrevistas "em profundidade" na pesquisa qualitativa em administração: pistas teóricas e metodológicas. In: Simpósio de Administração da Produção, Logística e Operações Internacionais. XV SIMPOI, São Paulo. Anais... São Paulo: Fundação Getúlio Vargas, 1-12.

Revista Viagem e Turismo; Ibope Inteligência. (2011). Quem é o viajante brasileiro? Recuperado em 15, fevereiro, 2018, dehttp://www.viagembrasil.tur.br/fotos/arquivos/2962.pdf

Rhoden, S., Hunter-Jones, P., \& Miller, A. (2016). Tourism experiences through the eyes of a child. AnnalsofLeisureResearch, 19(4), 424-443.

Sakowski, P. A. M. (2015). Mensurando o emprego no setor turismo no Brasil: do nível nacional ao regional e local. Instituto de Pesquisa Econômica Aplicada (IPEA), n. 2073.

Schänzel, H. A., \& Smith, K. A. (2014). The socialization of families away from home: group dynamics and family functioning on holiday. Leisure Sciences, 36(2), 126-143.

Shaw, S. M., Havitz, M. E., \& Delemere, F. M. (2008). "Idecided to invest in my kids' memories": family vacations, memories, and the social construction of the family. Tourism, Culture \& Communication, 8(1), 13-26.

UNESCO. (2017). Cidade Histórica de Ouro Preto. Recuperado em 02, novembro, 2017, de http://www.unesco.org/new/pt/brasilia/culture/world-heritage/list-of-world-heritage-inbrazil/historic-town-of-ouro-preto/ 
Vaz, G. N. (1999). Marketing turístico: receptivo e emissivo - um roteiro estratégico para projetos mercadológicos públicos e privados. São Paulo: Pioneira.

Yin, R. K. (2001). Estudo de caso: planejamento e métodos. (2aed.). Porto Alegre: Bookman.

FORMATO PARA CITAÇÃO DESTE ARTIGO

CERIBELI, H. B. \& CAMPOS, A. A. (2018). Produtos e serviços turísticos para a criança ofertados nos hotéis de Ouro Preto - MG. Revista de Turismo Contemporâneo, 6(2), 232250. 